\title{
Biochemical criteria for the development mechanisms of various reproduction disorders in dairy cows
}

\author{
INNA VENTSOVA", VLADIMIR SAFONOV \\ Department of Private Animal Science, Voronezh State Agrarian University named after Emperor Peter the Great. Mitchurina. 1, Voronezh 394087, \\ Russian. Tel./fax.: +7-9204004533, `email: innaventsova533@rambler.ru
}

Manuscript received: 13 September 2021. Revision accepted: 25 October 2021.

\begin{abstract}
Ventsova I, Safonov V. 2021. Biochemical criteria for the development mechanisms of various reproduction disorders in dairy cows. Biodiversitas 22: 4997-5002. The article presents the evaluation of peroxide, antioxidant, and hormonal conditions of highproducing red-and-white dairy cows in the physiological and pathological course of pregnancy and the postpartum period. The blood concentration of malonic dialdehyde, stable nitric oxide metabolites, S-nitrosothiols, vitamins $\mathrm{E}$ and C, carotin, gonadal, corticosteroid, and thyroid hormones, as well as activity of GPx, GR, SOD, catalase, and ceruloplasmin, were estimated to define major disorderprovoking factors. Analysis of the data shows that ketosis-gestosis syndrome during pregnancy, postpartum metritis, and gonadal dysfunction occur mainly because of oxidative stress in the context of unbalanced peroxide responses and antioxidant protection. Levels of malonic dialdehyde compared to healthy animals increased by $42.3 \%, 75 \%, 56.6 \%$, respectively, as also enzyme activities of GR by $26 \%, 68.1 \%, 30.1 \%$ and catalase by $17.3 \%, 45.1 \%$, and $23.9 \%$, correspondingly. The endocrine status indicators in the animals with ketosis-gestosis syndrome changed as follows: progesterone levels were $29.5 \%$ lower in cows, $17 \beta$-estradiol and cortisol were $20.8 \%$ and $14.7 \%$ lower, respectively. In animals with inflammatory uterine diseases and depressing reproductive glands, progesterone level was 2 and 3 times lower than in healthy animals, the content of cortisol was $17.6 \%$ and $25.1 \%$ lower, and testosterone decreased by $21.4 \%$ and $75.1 \%$, respectively.
\end{abstract}

Keywords: Antioxidant defense system, cows, gonadal dysfunction, hormones, ketosis-gestosis, metritis

\section{INTRODUCTION}

In recent decades, demand for agricultural products as a major food source for the global population has increased considerably due to population growth in different countries and the re-orientation of diets towards animal products.

Meanwhile, the production potential of dairy cows on many farms in the Russian Federation has increased considerably following the systematic improvement of the genetic pool and nutrition and housing conditions. However, many studies show that as cow productivity increases, the number of noncontagious animal diseases increases. These are primarily metabolic disorders and diseases that alter reproductive function like milk fever (ketosis), toxemia of pregnancy (gestosis), osteodystrophy, obstetrical palsy, and microelementosis (Nezhdanov et al. 2010; Niozas et al. 2019). These include large-scale livestock and high-intensity dairy complexes, which require solving numerous veterinary and health, zoo hygienic, organizational, economic, technical and technical issues. In conditions where physiological loads on animals increase significantly, the slightest technology breach creates preconditions for stressors that affect animal health. As a result, there is a decrease in milk and meat productivity and a violation of reproductive ability.

However, timely determination and study of some metabolic spectrum indicators of the animal body in the most vulnerable physiological periods of their lives are essential for the prediction and timely prevention of pathology development, which determines the livestock's productive longevity. Under the discussed problems of animal reproductive physiology and pathology, modern scientific literature focuses on oxidative stress issues. This problem refers to the oxidative change in proteins and lipids with excessive free radical oxidation (FRO) products. FRO is considered one of the predominant metabolic processes occurring spontaneously at the cell level to regulate the transformation of oxygen and the metabolism of proteins, nucleic acids, lipids, carbohydrates in the body. These processes ensure the energy supply to cells and the body as a whole, both in the normal condition and during the implementation of adaptive responses.

Molecular oxygen $\left(\mathrm{O}_{2}\right)$ plays a significant role in initiating FRO processes. Upon entering the body, it is immediately involved in oxidase and oxygenase-type reactions occurring on biological membranes and catalyzed by enzymes of the electron-transport system of mitochondria and the endoplasmic reticulum. Under normal conditions, approximately $95 \%$ of molecular oxygen is consumed by mitochondrial cytochrome oxidase and is involved in oxidative phosphorylation reactions to reduce two water molecules. In all living organisms, reactions involving the formation of reactive oxygen metabolites (ROMs) or reactive oxygen species (ROS), such as $\bullet \mathrm{O}_{2^{-}}, \mathrm{O}_{2^{-}}, \mathrm{H}_{2} \mathrm{O}_{2}, \mathrm{HO}_{2^{-}}$, and others, are constantly taking place (Carvalho and Moreira 2018). Although less than $5 \%$ of the molecular oxygen in enzymatic reactions is 
used during an incomplete reduction pathway with the formation of its reactive forms, this phenomenon is considered a compulsory component of vital activity and not merely a deviation from its primary usage route. Oxidative processes involving AOMs are integral to the existence of higher organisms, whose nongentropic state is maintained by changing an electron order of molecular oxygen due to its reduction.

ROMs react with numerous body biomolecules like proteins and amino acids, carbohydrates, lipids, and nucleic acids. By entering into oxidation reactions with polyunsaturated lipids, including fatty acid phospholipid residues, the main structural components of biological membranes, reactive oxygen species initiate the formation of some lipid peroxidation (LPO) products-peroxide radicals $\left(\mathrm{RO}_{2}^{-}\right)$. Their physiological meaning is to provide structural alteration of biomembranes and changes in their physicochemical properties. Furthermore, they can alter the phase state of the lipid biolayer, improve the hydration of the cell surface, and influence the conductivity of the membranes for the ions of small molecules. There is a concept whereby biological systems, confronted with the inevitable formation of free radicals, have developed specific mechanisms for their constructive use. For example, the formation of ROMs guarantees a cytotoxic action of phagocytes. Also, it regulates the mechanism of cell division, provides modulation of 'programmed' cell death by apoptosis, synthesis of several biologically active substances, and participates in the ovulation and fertilization processes.

However, the excessive ROM production by granulocytes, blood monocytes, and tissue macrophages under the violation of their complex utilization processes initiates an excessive accumulation of LPO products in the body cells, which causes oxidative stress. Besides, a high amount of LPO products result in the disconnection of oxidative phosphorylation in mitochondria, disruption of microsomal oxidation processes, changes in chromatin structural organization, distortion of reading genetic information in the cell (Khodos et al. 2017; Lanets et al. 2019), and subsequently, disruption of permeability and structural integrity of biomembranes.

Intense biological activity of various reactive oxygen and nitrogen forms and lipid and protein peroxidation products requires continuous biological antioxidant protection in the body. At the same time, antioxidants have a direct influence on the structure and function of subcellular formations. The most crucial element of this influence is the inhibition of biomembrane destruction processes and the disruption of protein enzyme function. Antioxidant defense mechanisms of the animal body play an exceptional role in maintaining homeostasis when the body interacts with changing environmental factors, as well as ensuring vital activity.

Strict regulation of FRO reactions is achieved through coordinated work of the system mechanisms, including enzymatic (superoxide dismutase, catalase, glutathione peroxidase, etc.) and non-enzymatic (vitamins $\mathrm{E}$ and $\mathrm{C}$, carotene, glutathione, ceruloplasmin, albumin, etc.) links that control the content of ROS, free radicals, and FRO molecular products. Antioxidant protection factors should also include a normal (adequate) level of lipid membrane components, a strictly defined range of membrane components, and their orderly organization to prevent the chaotropic effect. A weakening of any AOS link without any compensation activates FRO, and, therefore, can be one of the links in the pathogenesis of various animal diseases (Khodos et al. 2017; Carvalho and Moreira 2018; Raffaeli et al. 2018; Goshi et al. 2019; Yaguchi and Yaguchi 2019).

Copper-zinc-containing superoxide dismutase (SOD) is central to the enzyme link of the organism's AOS. It catalyzes the dismutation response of the superoxide radical followed by the formation of hydrogen peroxide $\left(\mathrm{H}_{2} \mathrm{O}_{2}\right)$ and molecular oxygen $\left(\mathrm{O}_{2}\right)$. The maintanence of optimal $\mathrm{H}_{2} \mathrm{O}_{2}$ exchange levels is achieved by the enzyme catalase and various peroxidases that catalyze the degradation of its molecules. Catalase is a hematincontaining enzyme that destroys $\mathrm{H}_{2} \mathrm{O}_{2}$ without accepting oxygen, and hydrogen peroxide act as an electron donor. Thus, this enzyme remains active for a long time with no need for activation energy, and the rate of $\mathrm{H}_{2} \mathrm{O}_{2}$ decomposition is restricted only by the rate of substrate diffusion at the active center of this enzyme.

The second defense line of the enzymatic AOS links is performed by selenium-dependent glutathione peroxidase (GPx), a component of the anti-peroxide complex that includes glutathione and glutathione reductase (GR). The GPx catalyzes the conversion of $\mathrm{H} 2 \mathrm{O} 2$ and hydroperoxides of fatty acids to hydrocompounds, which are metabolized by cellular systems, preventing the formation of hydroperoxides.

The effectiveness of the GPx mechanism for reducing hydroperoxides depends mainly on the level of the primary hydrogen donor for this reaction, i.e., glutathione. The maintenance of an adequate level of its reduced form is performed by a special enzyme glutathione reductase located in the same place as the glutathione-dependent antiperoxide enzymes. NADP- $\mathrm{H}_{2}$ is primarily used as a hydrogen donor to reduce oxidized glutathione.

In addition to SOD, the dismutation reaction of superoxide radicals is also carried out by a coppercontaining protein of $\alpha$-globulin serum fraction, i.e., ceruloplasmin (CP). Its special feature is its great resistance to the toxic action of reactive oxygen species, which enables it to maintain antiradical biological activity under conditions of intense ROS generation. Furthermore, unlike SOD protecting intracellular structures, $\mathrm{CP}$ acts in the blood, intercepts free radical oxygen forms, thereby protecting lipid structures from their harmful effect (Weidinger and Kozlov 2015).

Tocopherols are central to the non-enzymatic part of the body's AOS system, of which $\alpha$-tocopherol (vitamin E) is the most biologically active. This vitamin is a simple oxygen quencher, an oxygen radical anion acceptor, and a free radical interceptor, reacting with them directly at the break-up stage (Niki 2014; Zahrazadeh et al. 2018). The phenolic tocopherol radicals formed in this case are stable, do not interact with unsaturated fats, and are deactivated by chain reactions of LPO. Along with destroying oxygen and 
lipid peroxide radicals, $\alpha$-tocopherol creates a compact cell membrane architecture, preventing ROS attack on residues of unsaturated fatty acids from membrane phospholipids.

Ascorbic acid (vitamin C), beta-carotin and other carotenoids, as well as nitric oxide (NO•), also exhibit antiradical activity. Its protective effect is associated with the detoxification of super oxidizing radicals and its ability to enhance the activity of antioxidant enzymes (Nekrasov et al. 2017; Goshi et al. 2019). However, when nitric oxide is produced in excess, it can increase the adverse effects of ROS and present a cytotoxic effect (Nekrasov et al. 2017; Goshi et al. 2019; Yaguchi and Yaguchi 2019).

\section{Task statement}

Unfortunately, when the balance between the formation of pro-oxidants and the functioning of the antioxidant system in the body is disrupted, particularly under a variety of exogenous stressors, the free radical formation can become uncontrollable, disrupt cell respiration, and cause multiple adverse effects, including in reproductive function (Boudjellaba et al. 2018).

Thus, the purpose of this study was to determine the role of some biochemical parameters in the pathogenesis of different reproduction conditions in dairy cows. In addition, the objective of this work was to identify the characteristics of the FRO and AOS system functioning in dairy cows with normal and pathological pregnancies and postpartum periods.

\section{MATERIALS AND METHODS}

The studies were performed on red-and-white cows belonging to the "Druzhba" livestock farm in the Voronezh region with average annual milk productivity of 6.5 to 6.7 thousand kg. Experiment included cows with physiological course of pregnancy $(n=12)$ and postpartum period $(n=17)$, with clinical signs of gestosis $(n=18)$, acute postpartum purulent-catarrhal endometritis $(n=28)$, and ovarian dysfunction as their hypo-function $(n=12)$ in the experiment. Conventional methods assessed the clinical condition of the animals: visual examination-habitus, skin, and hair condition, the color of skin and visible mucous membranes, presence or absence of edema; palpation-the condition of lymph nodes, presence or absence of edema, condition of joints, pulse and respiratory rate measurement; the condition of genitals was estimated by transrectal palpation. Besides, such instrumental methods as body temperature measurement, heart and lung auscultation were applied. For assessing the course of LPO processes and the condition of AOS, the content of malonic dialdehyde (MDA), the sum of stable nitric oxide metabolites (NO-), S-nitrosothiols (RSNOs), the activity of SOD, catalase, GPx, GR, CP, as well as concentrations of vitamin E and C were determined in venous blood with standard research methods (Retzky et al. 2005). Hormonal status was assessed by determining plasma gonadal, corticosteroid, and thyroid hormones by enzyme immune analysis. The experimental data were processed through accepted mathematical and statistical methods in biology and medicine using Statistica 6.0 software. The significance of the differences was evaluated using the Student t-test. The differences were considered statistically significant at the level of significance $\mathrm{P}<0.05$.

\section{RESULTS AND DISCUSSION}

The assessment results of the LPO-AOS state during physiological (normal) pregnancy and the appearance of clinically pronounced gestosis (Table 1) showed that this condition develops in animals in the context of FRO process activation. It was proved by higher blood concentration of MDA (by $42.3 \%, \mathrm{P}<0.05$ ) and stable nitric oxide metabolites (by $31.9 \%$ ), and the increased activity of antioxidant defense enzymes as an expression of the compensatory response to the harmful action of LPO products. The GPx activity surpassed healthy animals by $26.0 \%$, and catalase activity increased by $17.3 \%$. At the same time, the strength of the AOS nonenzymatic component was at a lower level. Vitamin E content dropped by $44.5 \%(\mathrm{P}<0.05)$ and vitamin $\mathrm{C}$-by $20.8 \%$, and $\mathrm{CP}$ activity decreased by $5.6 \%$. This could be explained by increased expenditures on the neutralization of LPO toxics.

A negative consequence of the prooxidants accumulation in animals, demonstrated by oxidative stress, was a change in their hormonal state (Table 2). The level of progesterone in the blood of these cows relative to clinically healthy animals was $42.5 \% \quad(\mathrm{P}<0.05)$, testosterone, $53.8 \%(\mathrm{P}<0.05)$, estradiol $-17 \beta, 78.7 \%$, and cortisol, $74.6 \%$. Such figures reflect the functional insufficiency development of the fetal-placentary complex in cows, with all the negative consequences for the reproductive system of animals and the viability of calves born.

It is important to note that the LPO-AOS condition analysis in cows during the physiological course of the postpartum period and the postpartum metritis and gonadal dysfunction development showed a normal course of involutional processes in the genitals to be characterized by the optimal level of FRO (Table 3). Thus, the data presented in the table are consistent with the standards for clinically healthy animals and the phase of prenatal stress and labor stress relief.

Table 1. Indicators of the LPO-AOS status in cows during normal and pathological pregnancy

\begin{tabular}{|c|c|c|}
\hline Indicator & Normal & Gestosis \\
\hline $\mathrm{MDA}^{*}, \mu \mathrm{M} / 1$ & $1.04 \pm 0.14$ & $1.48 \pm 0.14^{\times}$ \\
\hline $\mathrm{NO}^{*}, \mu \mathrm{M} / 1$ & $60.1 \pm 8.02$ & $79.3 \pm 8.19$ \\
\hline GPx, mM G-SH/l-min & $14.6 \pm 1.54$ & $18.4 \pm 2.58$ \\
\hline Catalase, $\mathrm{mM} \mathrm{H}_{2} \mathrm{O}_{2} / \mathrm{L}$-min & $30.1 \pm 1.26$ & $35.3 \pm 2.44$ \\
\hline Vitamin $\mathrm{E}, \mu \mathrm{M} / 1$ & $11.2 \pm 0.89$ & $7.7 \pm 0.93^{\times}$ \\
\hline Vitamin $\mathrm{C}, \mathrm{mM} / \mathrm{l}$ & $14.5 \pm 5.73$ & $12.0 \pm 1.69$ \\
\hline $\mathrm{CP}, \mu \mathrm{M}$ benzoquinone/L'min & $284.3 \pm 11.08$ & $268.5 \pm 9.68$ \\
\hline
\end{tabular}


Table 2. Concentration of steroid hormones in the blood plasma of cows during physiological (normal) and pathological (gestosis) pregnancy (ng/mL)

\begin{tabular}{lcc}
\hline \multicolumn{1}{c}{ Indicator } & Normal & Gestosis \\
\hline Progesterone, $\mathrm{ng} / \mathrm{mL}$ & $24.7 \pm 4.62$ & $10.5 \pm 2.09^{\times}$ \\
Testosterone, $\mathrm{ng} / \mathrm{mL}$ & $1.3 \pm 0.22$ & $0.7 \pm 0.09^{\times}$ \\
Estradiol- $17 \mathrm{\beta}, \mathrm{pg} / \mathrm{mL}$ & $273.4 \pm 38.40$ & $215.2 \pm 17.90$ \\
Cortisol, $\mathrm{ng} / \mathrm{mL}$ & $32.7 \pm 5.79$ & $24.4 \pm 3.01$ \\
\hline Compared with the norms: ${ }^{\times}: \mathrm{P}<0.05,{ }^{\times \times}: \mathrm{P}<0.01,{ }^{\times \times \times}: \mathrm{P}<0.001$
\end{tabular}

In cows with inflammatory uterine diseases, LPO processes are quite active, as evidenced by the blood level of MDA exceeding that in clinically healthy animals by $75 \%$. This trend is probably due to a sharp increase in the production of neutrophils and ROS macrophages observed during the inflammatory process development. At the same time, these animals are characterized by the compensatory inclusion of the AOS enzyme link mechanisms (Carvalho and Moreira 2018). Bloodstream GPx activity in diseased cows was $68.1 \%(\mathrm{P}<0.01)$ higher than in healthy animals, that of GR $14.8 \%(\mathrm{P}<0.05)$ higher, SOD 45.2\% $(\mathrm{P}<0.001)$, and catalase $45.1 \%(\mathrm{P}<0.001)$. However, the slow growth of GR activity relative to GPx may indicate an insufficient functional potential for glutathione AOS binding and failure to correctly fill the pool with reduced glutathione.

Meanwhile, there has been a significant decrease in the potency of non-enzymatic AOS in diseased animals. Vitamin E content in their bloodstream was $35.9 \%$ lower $(\mathrm{P}<0.01)$, that of carotin $36.4 \% \quad(\mathrm{P}<0.01)$ lower, and ceruloplasmin activity dropped by $22.6 \% \quad(\mathrm{P}<0.05)$. In general, these factors disable adequate maintenance of the LPO processes at a relatively stable level, which can be a precondition for damages to cellular structures of endomyometrium and inflammations development. Nitric oxide production in these cows also increased by 2.9 times $(\mathrm{P}<0.001)$. The source of his generation is immunecompetent cells, macrophages and neutrophils. Meanwhile, the quantity of S-nitrosothiols, the nitric oxide deposit, was $12.4 \%$ lower.

Oxidative stress is known to negatively affect the function of the adrenal, thyroid, and endocrine glands, especially the ovaries. The development of the inflammation process in the uterus occurs in the context of their low activity. The progesterone concentration in their blood was 2.3 times lower than in healthy animals, that of testosterone decreased by $28.0 \%$, cortisol by $25.1 \%$, and triiodothyronine by $20.6 \%$ (Table 4 ).

Intense lipid peroxidation processes were also observed in cows suffering from depression of the reproductive gland. The MDA blood concentration exceeded the level of cycling animals by $56.6 \%(\mathrm{P}<0.001)$, the activity of GPx was $30.1 \%(\mathrm{P}<0.01)$ higher, that of GR increased by $10.2 \%$ $(\mathrm{P}<0.05)$, and SOD and catalase was $31.5 \%(\mathrm{P}<0.001)$ and $23.9 \%(\mathrm{P}<0.001)$ higher, accordingly. The blood level of vitamin $\mathrm{E}$ in ovarian hypofunctions was $67.7 \%$ lower than in healthy animals. It can be assumed that the altered generative and hormonal function of reproductive glands is directly related to the increased course of FRO processes. The hormonal status of infertile cows with ovarian hypofunctions is characterized by deficient gonadal and thyroid hormones in the blood (Table 4). Evaluation of the nitric oxide system in cows with ovarian hypofunction also showed low blood concentrations of both stable $\mathrm{NO} \bullet$ and S-nitrosothiol metabolites, the difference in their content being 2.57 and 1.42 times, respectively.

\section{Discussion}

The quantity and quality of the products obtained unquestionably depend on the animal's health, its adaptability to industrial habitat technologies, and, according to many scientists, genetic factors. Currently, highly efficient technologies based on mechanized and automated production lines are employed extensively in obtaining animal produce. The use of these technologies aims to meet the maximum biological requirements of animals. Highly productive animals are characterized by intensive metabolism, reduced adaptability and increased sensitivity to stress in the face of changing technological conditions. These animals react to any technical deviation with metabolic disorders, deteriorating health, and reduced productive longevity (Semenov et al. 2017; Ventsova et al. 2019).

Table 3. Indicators of the LPO-AOS status in cows with physiological (normal) and pathological (metritis) course of the postpartum period

\begin{tabular}{|c|c|c|c|}
\hline Indicator & Normal & Metritis & Hypofunction of the gonads \\
\hline$\overline{\mathrm{MDA}}, \mu \mathrm{M} / \mathrm{L}$ & $0.99 \pm 0.05$ & $1.74 \pm 0.40$ & $1.55 \pm 0.05^{\times \times x}$ \\
\hline GPx, mM G-SH/L-min & $9.3 \pm 0.32$ & $15.7 \pm 0.44^{\times x}$ & $12.1 \pm 0.65^{\times x}$ \\
\hline GR, $\mu \mathrm{M}$ G-SS-G/L-min & $292.2 \pm 10.88$ & $335.3 \pm 9.06^{\times}$ & $322.0 \pm 7.24^{\times}$ \\
\hline SOD, units/mg Hb & $0.73 \pm 0.02$ & $1.06 \pm 0.04^{\times \times x}$ & $0.96 \pm 0.06^{x \times x}$ \\
\hline Catalase, $\mathrm{mM} \mathrm{H}_{2} \mathrm{O}_{2} / \mathrm{L}$-min & $25.9 \pm 0.57$ & $37.6 \pm 0.63^{x \times x}$ & $32.1 \pm 0.84^{\times \times x}$ \\
\hline Vitamin $\mathrm{E}, \mu \mathrm{M} / \mathrm{L}$ & $23.9 \pm 3.48$ & $15.3 \pm 0.93^{x \times}$ & $16.2 \pm 2.79$ \\
\hline Carotin, $\mu \mathrm{g} \%$ & $475.8 \pm 37.1$ & $302.4 \pm 37.7^{\times x}$ & $326.5 \pm 58.9$ \\
\hline $\mathrm{CP}, \mu \mathrm{M}$ benzoquinone/L-min & $315.6 \pm 12.1$ & $244.0 \pm 10.1^{\times}$ & - \\
\hline $\mathrm{NO}-, \mu \mathrm{M} / \mathrm{L}$ & $47.8 \pm 0.29$ & $138.7 \pm 7.14^{\times \times x}$ & $20.6 \pm 2.21$ \\
\hline $\mathrm{RSNO}, \mathrm{nM} / \mathrm{mL}$ & $3046 \pm 139.2$ & $2709 \pm 42.5$ & $2258 \pm 34.3$ \\
\hline
\end{tabular}

Note: *MDA: malondialdehyde; GPx: glutathione peroxidase; GR: glutathione reductase; SOD: superoxide dismutase; CP: ceruloplasmin. NO*: nitric oxide; RSNO: S-nitrosothiols; Compared with the norms: ${ }^{\times}$: $\mathrm{P}<0.05,{ }^{\times x}: \mathrm{P}<0.01,{ }^{\times \times x}$ : $\mathrm{P}<0.001$ 
Table 4. The concentration of steroid and thyroid hormones in the blood plasma of cows in physiological (normal) and pathological (metritis) course of postpartum period $(\mathrm{nM} / \mathrm{L})$

\begin{tabular}{lccc}
\hline \multicolumn{1}{c}{ Indicator } & Normal & Metritis & $\begin{array}{c}\text { Hypofunction } \\
\text { of the gonads }\end{array}$ \\
\hline Progesterone & $4.25 \pm 1.02$ & $1.82 \pm 0.22^{\times}$ & $1.04 \pm 0.25^{\times \times}$ \\
Testosterone & $9.8 \pm 1.94$ & $7.7 \pm 2.30$ & $2.44 \pm 0.40^{\times \times}$ \\
Estradiol-17 & $0.72 \pm 0.01$ & $0.77 \pm 0.02$ & $0.67 \pm 0.10$ \\
Cortisol & $40.2 \pm 11.2$ & $33.1 \pm 4.41$ & $29.0 \pm 7.97$ \\
Triiodothyronine & $2.25 \pm 0.86$ & $1.77 \pm 0.82$ & $1.86 \pm 0.70$ \\
\hline Compared with the norms: ${ }^{\times}: \mathrm{P}<0.05,{ }^{\times \times}: \mathrm{P}<0.01,{ }^{\times \times \times}: \mathrm{P}<0.001$
\end{tabular}

In Russia, as elsewhere in the world, there is a dramatic decline in the breeding capacity of cows, which has become one of the main problems of this industry. The maximum increase in livestock productivity without the use of innovative technologies for the selection and breeding of dairy cattle and ignoring their physiological needs leads to functional overload of the body's organs and systems. Numerous diseases can therefore develop during pregnancy and disrupt the development of the fetus. Some researchers believe (Avdeenko et al. 2016; Chechenikhina and Loretz 2018) that the observed disturbances in reproductive function of cows with enhanced genetic potential for dairy productivity are associated mainly with significant and inadequate changes in metabolism. Consequently, the way to solve the problem of gestosis in high-producing dairy cattle at the end of pregnancy is to study the role of metabolic disorders that facilitate the development of subclinical ketosis and gestosis in pathogenesis. Furthermore, the concept was recently promoted (Avdeenko et al. 2016), indicating that obstetric and gynecological pathology in dairy cattle is a by-product of the mechanisms necessary for achieving the genetic program of pregnancy development and fetal formation. In this case, damage to the tissue structures of the reproductive organs may be caused by metabolic processes. In particular, they were activating free radical oxidation processes to enhance the synthesis of prostaglandins and steroid hormones. Such processes result in the formation and accumulation of reactive oxygen species (superoxide, hydroxide, hydroperoxide radicals, hydrogen peroxide, singlet oxygen species), acting as a universal non-specific metabolic link in the development of many pathological conditions (Zielonka et al. 2012).

Moreover, it has become increasingly evident that active oxygen metabolites and nitric oxide as a universal regulator of physiological functions and cell metabolism are involved in the pathogenesis of reproductive system disorders. Nitric oxide also provides protective and adaptive responses to stress and adaptive responses in mammals. Therefore, investigating some biochemical indices that affect the LPO-AOS and nitric oxide systems in the genesis of obstetric and gynecological pathologies comes to one of the first places when addressing issues related to the conservation of animal fertility (Phipps et al. 2016; Safonov et al. 2018a). Such studies are of particular importance relative to the state of the endocrine system that controls the level of peroxidation, nucleic acid and protein synthesis, lipid exchange, homeostasis, and hormonogenesis processes.

It may be assumed that insufficient nitric oxide generation in animals with reproductive pathology is associated with inhibition of NO synthase. Since nitric oxide is included in the control of gonadotropin release hormone secretion by the hypothalamus and the luteinizing hormone by the vital functions of the pituitary gland and oocyte (Boudjellaba et al. 2018; Safonov et al. 2018b), its low concentration leads to impairment of generative and hormonal ovary function. On the other hand, the relationship between the formation of $\mathrm{NO} \bullet$ in the body and the level of gonadal steroids in the bloodstream was established by foreign researchers (Phipps et al. 2016) and in this work (Table 2, 3). Such a relation gives reasons to assume that reduced production of $\mathrm{NO} \cdot$ in cows with the ovarian disease is subsequently aggravated by a low level of gonadal steroid secretion following the evolution of causal relationships in the physiological system nitric oxide - hypothalamus - hypophysis - gonads.

According to some researchers (Simensen et al. 2010), the economic damage from ketosis-gestosis syndrome and metra-ovariopathies implies reduced use of the most productive animals by $2-4$ years, a $30-50 \%$ decrease in milk productivity, loss of live weight, forced culling, etc.

In conclusion, the development of ketosis-gestosis in pregnant cows and metra-ovariopathy after calving occurs in the context of the activation of LPO processes and the increase of toxins from peroxide oxidation. Their excessive accumulation causes the mobilization of enzyme antioxidants, increased consumption, and decreased plasma concentration of natural antioxidants like vitamins $\mathrm{E}$ and $\mathrm{C}$ and carotin. The AOS activity and the balance between pro-oxidants and antioxidants largely determine the maintenance of hormone homeostasis in the body and the normal functioning of the animal reproduction system. The findings of this study revealed new aspects in understanding the pathogenesis of gestational complications and post-partum meta-ovariopathies and provided opportunities for their treatment and prevention.

\section{ACKNOWLEDGEMENTS}

The authors did not receive support from any organization for the submitted work. Therefore, the authors have no conflicts of interest to declare that they are relevant to the content of this article.

\section{REFERENCES}

Avdeenko VS, Donnik IM, Lorets OG, Babukhin SN, Rykhlov AS, Molchanov AV. 2016. Mechanism of ketosis-gestosis syndrome in pregnant cows and the effectiveness of antioxidant drugs. Agrar Bull Urals 8: 4-9.

Boudjellaba S, Ainouz L, Tennah S, Temim S, Iguer-Ouada M. 2018. Reproduction performance and blood biochemical parameters in dairy cows: Relationship with oxidative stress status. Vet World 11: 883888. DOI: 10.14202/vetworld.2018.883-888 
Carvalho C, Moreira PI. 2018. Oxidative stress: A major player in cerebrovascular alterations associated to neurodegenerative events. Front Physiol 9: 806. DOI: 10.3389/fphys.2018.00806

Chechenikhina OS, Loretz OG. 2018. Indicators of productive longevity of black-motley cows with tethered and untethered housing. Bull Stavrop Agroind Complex 3: 55-59.

Goshi E, Zhou G, He Q. 2019. Nitric oxide detection methods in vitro and in vivo. Med Gas Res 9: 192-207. DOI: 10.4103/2045-9912.273957

Khodos MY, Kazakov YE, Vidrevich MB, Brainina HZ. 2017. Monitoring of oxidative stress in biological objects. Bull Ural Med Acad Sci 14: 262-274

Lanets OV, Grin VA, Semenenko MP. 2019. Oxidative stress in cattle and prospects for its pharmacocorrection. Proc Krasnodar Sci Center Zootech Vet Med 8: 269-274.

Nekrasov AA, Popov NA, Fomichev YP, Fedotova EG. 2017. Genesis of metabolic disorders and its regulation in cows in transit. Sci Notes Vitebsk State Acad Vet Med 53: 245-249.

Nezhdanov AG, Retskii MI, Alekhin Yu N, Safonov VA, Shushlebin VI, Papin NE, Brekhov TP, Shishkina EV. 2010. Clinico-hematologic and biochemical status of cows at gestosis. Agric Biol 45: 118-123.

Niki E. 2014. Role of vitamin E as a lipid-soluble peroxyl radica scavenger: In vitro and in vivo evidence. Free Radic Biol Med 66: 3 12. DOI: $10.1016 /$ j.freeradbiomed.2013.03.022

Niozas G, Tsousis G, Malesios C, Steinhöfel I, Boscos C, Bollwein H, Kaske M. 2019. Extended lactation in high-yielding dairy cows. II. Effects on milk production, udder health, and body measurements. J Dairy Sci 102: 811-823. DOI: 10.3168/jds.2018-15117

Phipps E, Prasanna D, Brima W, Jim B. 2016. Preeclampsia: Updates in pathogenesis, definitions, and guidelines. Clin J Am Soc Nephrol 11: 1102-1113. DOI: $10.2215 /$ cjn. 12081115

Raffaeli G, Ghirardello S, Passera S, Mosca F, Cavallaro G. 2018. Oxidative stress and neonatal respiratory extracorporeal membrane oxygenation. Front Physiol 9: 1739. DOI: 10.3389/fphys.2018.01739

Retzky MI, Shakhov AG, Shushlebin VI, Samotin AM. 2005. Methodical Recommendations on the Diagnosis, Therapy and Prevention of
Metabolic Disorders in Productive Animals. Russian Academy of Agricultural Sciences, Moscow.

Safonov V, Bliznetsova G, Nezhdanov A, Shabunin S, Pasko N. 2018a. Stable nitrogen ox- ide metabolites and S-nitrosotiols in blood plasma of cows with reproductive organs pathology. Reprod Domest Anim 53: 191

Safonov VA, Mikhalev VI, Chernitsky AE. 2018b. Antioxidant status and functional state of the respiratory system in newborn calves with intrauterine developmental delay. Agric Biol 53: 831-841. DOI: 10.15389/agrobiology.2018.4.831eng

Semenov VG, Gerasimova NI, Volkov AV, Lopatnikov AV. 2017. Realization of Reproductive and Productive Qualities of Cattle. Chuvash State Agricultural Academy, Cheboksary.

Simensen E, Osteras O, Boe KE, Kielland C, Ruud LE, Naess G. 2010. Housing system and herd size interactions in Norwegian dairy herds; associations with performance and disease incidence. Acta Vet Scand 52: 52-54. DOI: 10.1186/1751-0147-52-14

Ventsova IY, Vostroilov AV, Safonov VA. 2019. Metabolic monitoring of adaptation processes at pregnancy final stage in different breeds of imported cattle in the Central Black Soil region. Reprod Domest Anim 54: 120.

Weidinger A, Kozlov AV. 2015. Biological activities of reactive oxygen and nitrogen species: Oxidative stress versus signal transduction. Biomolecules 5: 472-484. DOI: 10.3390/biom5020472

Yaguchi J, Yaguchi S. 2019. Evolution of nitric oxide regulation of gut function. Proc Natl Acad Sci USA 116: 5607-5612. DOI: 10.1073/pnas.1816973116

Zahrazadeh M, Riasi A, Farhangfar H, Mahyari SA. 2018. Effects of close-up body condition score and selenium-vitamin $\mathrm{E}$ injection on lactation performance, blood metabolites, and oxidative status in high-producing dairy cows. J Dairy Sci 101: 10495-10504. DOI: 10.3168/jds.2017-14196

Zielonka J, Zielonka M, Sikora A, Adamus J, Joseph J, Hardy M, Ouari O. 2012. Global profiling of reactive oxygen and nitrogen species in biological systems: High-throughput real-time analyses. J Biol Chem 5: 2984-2995. DOI: 10.1074/jbc.M111.309062 